\title{
Preemptive versus postoperative lumiracoxib for analgesia in ambulatory arthroscopic knee surgery
}

\author{
Joachim Grifka' \\ Rudolf $\mathrm{Enz}^{2}$ \\ Joachim Zink ${ }^{3}$ \\ Jean Louis Hugot ${ }^{4}$ \\ Andreas Kreiss ${ }^{5}$ \\ Udayasankar Arulmani ${ }^{4}$ \\ Vincent $Y^{6}{ }^{6}$ \\ Rosemary Rebuli ${ }^{4}$ \\ Gerhard Krammer ${ }^{4}$ \\ 'Orthopädische Klinik der \\ Univ, Regensburg, Germany; \\ ${ }^{2}$ DiaMed Centrum, Klinik \\ Neuendettelsau, Neuendettelsau, \\ Germany; ${ }^{3}$ Orthopädische \\ Fachpraxisgemeinschaft, Jena Zwätzen, \\ Deutschland, Germany; ${ }^{4}$ Novartis \\ Pharma AG, Basel, Switzerland; \\ ${ }^{5}$ Novartis Pharma GmbH, Nürnberg, \\ Germany; ${ }^{6}$ Novartis Pharma AG, East \\ Hanover, NJ, USA
}

\begin{abstract}
We compared the efficacy and safety of preemptive vs postoperative dosing of lumiracoxib $400 \mathrm{mg}$ in patients undergoing minor ambulatory arthroscopic knee surgery. Eligible patients were randomized to preemptive lumiracoxib, postoperative lumiracoxib, and placebo. The main efficacy parameter was pain intensity (PI) (0-100 mm visual analog scale) in the target knee upon movement, 2 hours after surgery. Other efficacy variables included PI in the target knee at rest and upon movement at 1, 3, 4, and 24 hours, time to first rescue medication intake. In the lumiracoxib preemptive and postoperative groups, the estimated treatment difference compared to placebo for primary endpoint was -4.0 (95\% CI: $-9,-1 ; p=0.007)$ and $-3.5(95 \%$ CI: $-8.5,0 ; p=0.052)$, respectively. There was no statistical significant difference between two active treatment groups $(p=0.602)$. Both preemptive and postoperative lumiracoxib resulted in significantly lower PI scores at rest and after movement at all time-points and no statistically significant difference was observed between the active treatments. Time to rescue medication intake was comparable for both active treatments. The proportion of adverse events was similar among all groups. We conclude that the efficacy of lumiracoxib $400 \mathrm{mg}$ is not affected by the timing of administration (preemptive or postoperative).

Keywords: arthroscopy, arthroscopic knee surgery, lumiracoxib, NSAIDs, postoperative pain, preemptive dosing
\end{abstract}

\section{Introduction}

Arthroscopy has reduced morbidity and duration of hospitalization related to orthopedic surgery and the knee is the most commonly arthroscoped joint (Villar 1994). The sensory signals, following surgical trauma however trigger a prolonged state of increased excitability in the central nervous system (CNS) and later, result in the development of chronic pain after surgery (Woolf and Chong 1993). Hence many researchers have focused on methods to prevent these central neuroplastic changes through the utilization of preemptive or preventive analgesic techniques (Reuben and Buvanendran 2007).

Nonsteroidal antiinflammatory drugs (NSAIDs) attenuate the inflammatory response; reduce the peripheral sensitization and the induction, and maintenance of central sensitization. The central analgesic actions of NSAIDs may contribute to a preemptive analgesic effect by averting spinal prostaglandin synthesis and reducing pre- and postsynaptic release of neurotransmitters from the primary afferent terminals and spinal interneurons (Katz 2001).

One of the major disadvantages of administering traditional NSAIDs before orthopedic surgery is the risk of perioperative bleeding. This risk is attributed to antiplatelet effects of traditional NSAIDs via. cyclo-oxygenase (COX)-1 isoenzyme (Robinson et al 1993; Legeby et al 2005). Selective COX-2 inhibitors have emerged 
as a class of analgesic agents that offer pain relief similar to nonselective NSAIDs without compromising platelet aggregation and with reduced gastrointestinal (GI) toxicity (Romsing and Moiniche 2004). Reuben and Connelly (2000) have shown that preoperative administration of selective COX-2 inhibitors are effective in the treatment of postoperative pain, and are not associated with an increase in perioperative blood loss.

Perioperative use of a COX-2 inhibitor reduces opioid consumption, pain, vomiting, sleep disturbance, and improves the range of motion after total knee arthroplasty (Buvanendran et al 2003). Lumiracoxib is the first carboxyl, nonsulphur-containing, selective COX-2 inhibitor with anti-inflammatory, analgesic, and antipyretic effects comparable with traditional NSAIDs, but with much improved GI safety profile (Schnitzer et al 2004; Esser et al 2005). Lumiracoxib has unique pharmacokinetics as its metabolites are retained in the inflamed tissues, and its synovial fluid half-life is higher than plasma half-life (Scott et al 2004).

Lumiracoxib is effective in treating acute pain conditions such as postoperative dental pain (Kellstein et al 2004; Zelenakas et al 2004; Fricke et al 2008), acute gout (Willburger et al 2006), arthroplasty (Chan et al 2005), primary dysmenorrhoea (Daniels et al 2008), and sprains and strains (Kyle et al 2006). Lumiracoxib is indicated at a dose of $100 \mathrm{mg}$ once daily for chronic use in osteoarthritis, and at doses of $200 \mathrm{mg}$ or $400 \mathrm{mg}$ once daily for short-term use in acute pain indications. While liver toxicity is a known rare but serious side effect of all COX-2 inhibitors and traditional NSAIDs (Traversa et al 2003), there have been some specific concerns from health authorities regarding the hepatic profile of lumiracoxib. Australia withdrew lumiracoxib in August 2007 following reports of severe liver events occurring predominantly at doses higher than lumiracoxib $100 \mathrm{mg}$ once daily taken chronically. The US Food and Drug Administration (FDA) issued a nonapprovable letter in September 2007, citing concerns over the hepatic profile of lumiracoxib. This was followed by withdrawals in Canada, Europe, and a few other countries. Assessment of the benefit-risk profile of the drug is ongoing by a number of health authorities (Fleischmann et al 2008).

The present study was designed to compare the efficacy and safety of preemptive vs postoperative dosing of lumiracoxib 400 mg (Novartis Pharma AG, Basel, Switzerland) in patients who underwent minor ambulatory arthroscopic knee surgery.

\section{Methods}

This was a multi-center, randomized, double-blind, placebo-controlled, parallel-group study. The study was performed in compliance with the guidelines for good clinical practice and in accordance with the Declaration of Helsinki. Ethics committee approval from all participating institutions was obtained. Patients, investigator staff, persons performing the assessments, data analysts, and clinical team members were blinded to the identity of the treatment.

\section{Study populations}

Male or female outpatients (aged at least 18 years) who had signed a written informed consent and were scheduled for minor ambulatory arthroscopic knee surgery (eg, removal, trimming, shaving or repair of meniscal or articular cartilage including lavage) were included in the study, with the exclusion of only diagnostic arthroscopy. The determination of sample size was based on the results of a similarly designed single centre study (Reuben et al 2002).

Patients with a history of hypersensitivity or allergy to narcotics, NSAIDs or any COX-2 inhibitors, drug or alcohol abuse, peptic ulcer, gastroesophageal reflux disease, inflammatory bowel disease and any cardiovascular, hepatobiliary and pancreatic and renal disorder were excluded from the study. Patients taking anticoagulants and anti-platelet aggregation agents (except low-dose aspirin for cardioprotection) and pregnant or lactating females were also excluded.

All surgical procedures were performed under local anesthesia, using $30 \mathrm{ml}$ intra-articular bupivacaine $0.25 \%$. During surgery, patients received i.v. sedation with midazolam (1-3 mg) and propofol (10-100 $\mu \mathrm{g} / \mathrm{kg} / \mathrm{min})$, and, an additional $30 \mathrm{ml}$ of intra-articular bupivacaine $0.25 \%$ was injected through the arthroscope at the end of the surgery.

\section{Study design}

Eligible patients were randomized $(2: 2: 1)$ to receive lumiracoxib $400 \mathrm{mg}$ given preemptively (1 hour before the start of surgery), lumiracoxib $400 \mathrm{mg}$ given postoperatively (15 min after the completion of surgery), or placebo. Patients in the first group received a single dose of lumiracoxib $400 \mathrm{mg} 1$ hour before surgery and a placebo tablet $15 \mathrm{~min}$ after surgery (Preemptive group), patients in the second group received a placebo tablet 1 hour before surgery and a single dose of lumiracoxib $400 \mathrm{mg} 15 \mathrm{~min}$ after surgery (Postoperative group), and patients in the third group received a placebo tablet both 1 hour before and again 15 min after surgery (Placebo group). Patients were monitored during the 
24-hour period after the surgery and they were asked to come back for a final visit approximately 24 hours after surgery.

Assessment of postoperative pain intensity was performed using a $0-100 \mathrm{~mm}$ visual analog scale (VAS). Pain intensity scores were recorded both at rest and after movement at 1, 2, 3,4 , and 24 hours after completion of surgery. The primary efficacy endpoint was the reduction in pain intensity in the target knee after movement at the 2 hour time-point. Pain score after movement was recorded immediately after the patient actively flexed the operated knee to the $90^{\circ}$ position. Missing pain intensity scores were imputed by last observation carried forward method (LOCF).

The secondary efficacy endpoints included the reduction in pain intensity at 1, 2, 3, 4 and 24 hour time-points while at rest and reduction in pain intensity at 1, 3, 4 and 24 hour time-points after movement, the time to first rescue medication intake, and the patient's global evaluation of response to the study medication (using a 'four-point' Likert scale at the end of the study when patients rated the study medication as either poor, fair, good, or excellent).

The use of oral paracetamol $500 \mathrm{mg}$ was permitted during the screening period until 12 hours before surgery. After surgery oral paracetamol $1000 \mathrm{mg}$ was provided as the rescue medication and if needed, addition of oral oxycodone $10 \mathrm{mg}$ was allowed. Systemic corticosteroids, opiates, anticoagulants, other NSAIDs and antiplatelet agents (except low-dose aspirin for cardioprotection) were not allowed as concomitant therapies. Safety assessments consisted of collecting all adverse events (AEs), serious adverse events (AEs meeting one of the following criteria: fatal or life-threatening; resulting in disability/incapacity; birth defects; requires or prolongs hospitalization; or is medically significant, ie, defined as an event that jeopardizes the patient or may require intervention to prevent one of the outcomes listed above), with their severity, duration and relationship to study drug, and pregnancies. The occurrence of AEs was sought by nondirective questioning or they were detected when volunteered by the patient. Adverse events were summarized by presenting the number and percentage of patients having any $\mathrm{AE}$, having an $\mathrm{AE}$ in each system organ class and having each individual AE. Adverse events were to be described by the investigator by severity (mild, moderate or severe AE). Assessments of physical condition and vital signs were also a part of the safety assessment.

\section{Statistical analyses}

The intent-to-treat (ITT) population was the primary population for efficacy analyses and consisted of all randomized patients who received at least one dose of study medication. The per-protocol (PP) population consisted of all ITT patients who were not major protocol violators. The safety population included all patients who received at least one dose of study medication. Assuming a dropout rate of $8 \%$, a total of 110 patients and at least 39 patients in the active treatment groups were required for the evaluation the primary efficacy variable. In order to minimize the number of patients treated with placebo, a 2:2:1 randomization scheme was used. Comparisons of median values of time specific pain intensity (both at rest and after movement) were made relative to placebo and between active treatments using the Wilcoxon's rank sum test stratified by the center and the Hodges-Lehmann estimate of the median difference. The time to first rescue medication was measured from the end of surgery using a logrank test, and Kaplan-Meier estimates for the fraction of patients who did not take rescue medication were plotted. Patient's global evaluations were summarized using the Cochran-Mantel-Haenszel test after adjusting for center.

\section{Results}

One hundred and ten patients were enrolled in the study and all of them were randomized $(2: 2: 1)$ to lumiracoxib preemptive $(n=45)$, lumiracoxib postoperative $(n=44)$, and placebo $(n=21)$ (Figure 1$)$. All patients completed the study without discontinuations. Patient demographics are shown in Table 1. Treatment groups were comparable for the mean weight, body mass index (BMI) and race. All patients were Caucasian. Majority of patients were in the age range of 41 to 64 years, with the placebo group having a smaller percentage of patients in the lower age group (less than 40) than the two active treatment arms.

The surgery performed was similar across the three groups. Removal of meniscal cartilage and shaving of articular cartilage were the most common types of surgery performed for all treatment groups. The duration of surgery was similar across the three treatment groups (mean values: 30.6-31.8 min). The lumiracoxib postoperative group had the lowest maximum duration (Table 2).

Preemptive dosing with $400 \mathrm{mg}$ lumiracoxib resulted in lower median pain intensity scores than postoperative dosing or placebo. The estimated difference in median pain intensity compared to placebo was statistically significant in both active treatment groups. Although the mean and median scores of pain intensity were lower for the lumiracoxib preemptive group than for the postoperative lumiracoxib group, the Hodges-Lehmann estimate of the difference was 


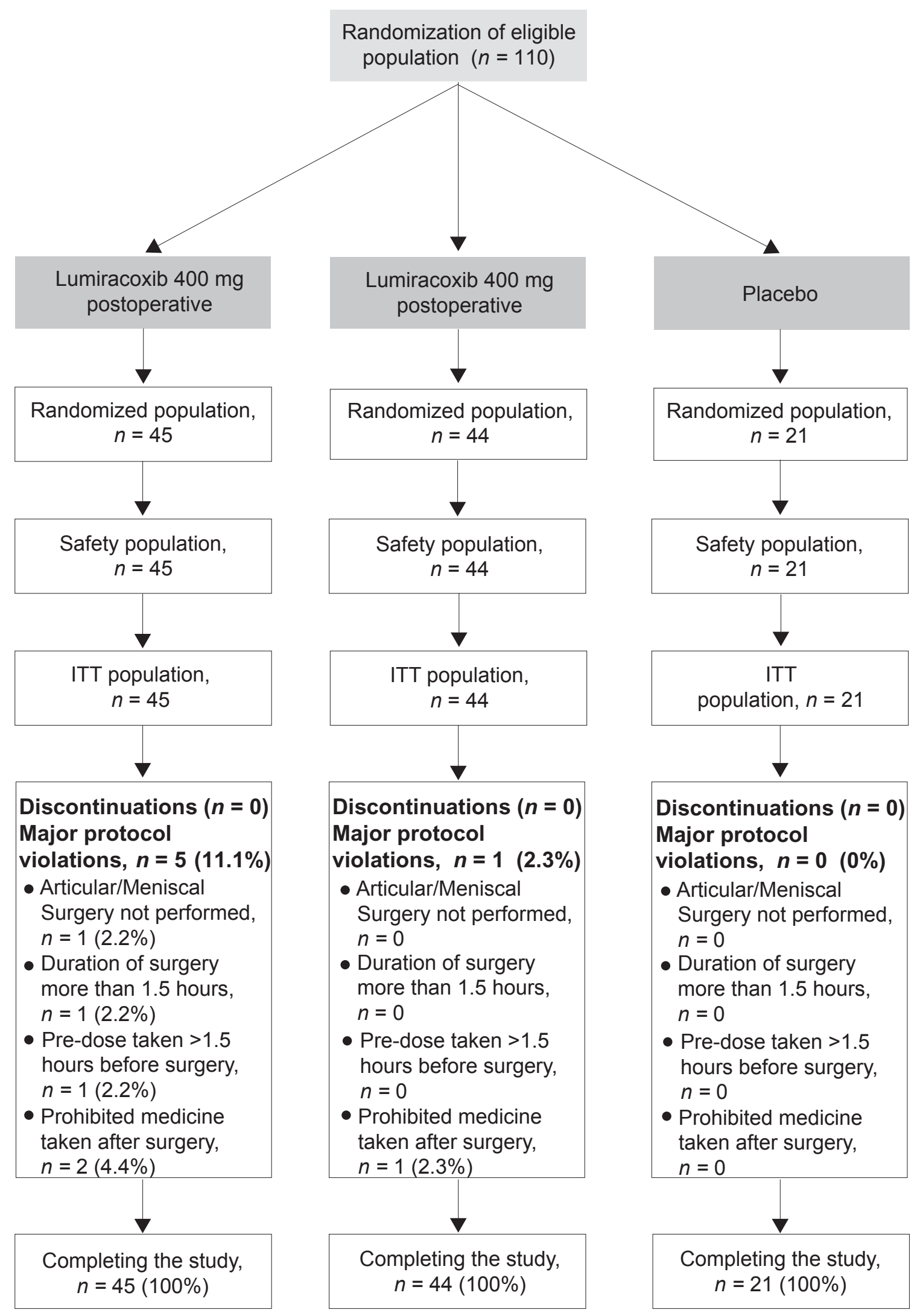

Figure I Patient disposition. 
Table I Demographic summary of the treatment groups (safety population)

\begin{tabular}{|c|c|c|c|c|}
\hline & $\begin{array}{l}\text { Lumiracoxib } 400 \mathrm{mg} \\
\text { preemptive } \mathrm{N}=45 \mathrm{n}(\%)\end{array}$ & $\begin{array}{l}\text { Lumiracoxib } 400 \mathrm{mg} \\
\text { postoperative } \mathrm{N}=44 \mathrm{n}(\%)\end{array}$ & $\begin{array}{l}\text { Placebo } N=21 \\
n(\%)\end{array}$ & $\begin{array}{l}\text { All groups } N=110 \\
n(\%)\end{array}$ \\
\hline Age (years) Mean \pm SD & $50 \pm 18.2$ & $51.8 \pm 13.8$ & $55.8 \pm 9.5$ & $51.8 \pm 15.1$ \\
\hline \multicolumn{5}{|l|}{ Age group $n(\%)$} \\
\hline $18-40$ years & $16(35.6)$ & $9(20.5)$ & I (4.8) & $26(23.6)$ \\
\hline $4 I-64$ years & 17 (37.8) & $27(6 I .4)$ & 14 (66.7) & $58(52.7)$ \\
\hline$>64$ years & $12(26.7)$ & $8(18.2)$ & $6(28.6)$ & $26(23.6)$ \\
\hline \multicolumn{5}{|l|}{ Gender $n(\%)$} \\
\hline male & $20(44.4)$ & $25(56.8)$ & $10(47.6)$ & $55(50.0)$ \\
\hline female & $25(55.6)$ & $19(43.2)$ & II (52.4) & $55(50.0)$ \\
\hline Race (Caucasian) n (\%) & $45(100)$ & $44(100)$ & $21(100)$ & $110(100)$ \\
\hline Weight $(\mathrm{kg})$ Mean \pm SD & $79.9 \pm 14.0$ & $82.1 \pm 16.0$ & $87.9 \pm 16.4$ & $82.3 \pm 15.4$ \\
\hline BMI $\left(\mathrm{kg} / \mathrm{m}^{2}\right)$ Mean $\pm \mathrm{SD}$ & $27.6 \pm 4.7$ & $28.01 \pm 5.7$ & $29.4 \pm 4.4$ & $28.1 \pm 5.1$ \\
\hline
\end{tabular}

Abbreviations: BMI, body mass index; SD, standard deviation.

however not statistically significant (Table 3 ). The results of per protocol (PP) analysis confirmed that both preemptive and postoperative lumiracoxib $400 \mathrm{mg}$ were significantly better at relieving pain following arthroscopic knee surgery than placebo, but preemptive dosing did not have a significant benefit over postoperative.

Both preemptive and postoperative lumiracoxib dosing resulted in significantly lower pain intensity scores than placebo at rest and after movement at all time-points, with the exception of postoperative dosing at rest at 1 hour and after movement at 2 hours. There was no statistically significant difference in pain intensity (at any time-point at rest and after movement) and time to first rescue medication intake between the active treatment groups (Figure 2A and B). The time to rescue medication intake was significantly longer for both preemptive $(p=0.003)$ and postoperative lumiracoxib groups $(p=0.001)$ compared with placebo (Figure 3 ). The use of the rescue medication use is summarized in Table 4.

Table 2 Surgical summary of the treatment groups (safety population)

\begin{tabular}{|c|c|c|c|c|}
\hline & $\begin{array}{l}\text { Lumiracoxib } 400 \mathrm{mg} \\
\text { preemptive } N=45\end{array}$ & $\begin{array}{l}\text { Lumiracoxib } 400 \mathrm{mg} \\
\text { postoperative } N=44\end{array}$ & Placebo $\mathbf{N}=\mathbf{2} \mid$ & Total $N=110$ \\
\hline $\begin{array}{l}\text { Duration of surgery (minutes) } \\
\text { Mean } \pm \text { SD }\end{array}$ & $31.8 \pm 14.8$ & $30.6 \pm 11.9$ & $31.7 \pm 17.8$ & $31.3 \pm 14.3$ \\
\hline \multicolumn{5}{|c|}{ Cartilage surgery, number (\%) of patients } \\
\hline Articular & $27(60.0 \%)$ & 27 (6I.4\%) & 15 (7I.4\%) & $69(62.7 \%)$ \\
\hline \multicolumn{5}{|l|}{ Type of surgery performed } \\
\hline Remove & $2(4.4 \%)$ & $4(9.1 \%)$ & 0 & $6(5.5 \%)$ \\
\hline Trimming & $5(11.1 \%)$ & $10(22.7 \%)$ & 7 (33.3\%) & $22(20.0 \%)$ \\
\hline Shave & $21(46.7 \%)$ & $15(34.1 \%)$ & $9(42.9 \%)$ & 45 (40.9\%) \\
\hline Repair & I (2.2\%) & I (2.3\%) & I (4.8\%) & $3(2.7 \%)$ \\
\hline Meniscal & $38(84.4 \%)$ & 37 (84.1\%) & $18(85.7 \%)$ & $93(84.5 \%)$ \\
\hline \multicolumn{5}{|l|}{ Type of surgery performed } \\
\hline Remove & 27 (60.0\%) & $33(75.0 \%)$ & 15 (7I.4\%) & 75 (68.2\%) \\
\hline Trimming & $7(15.6 \%)$ & 7 (15.9\%) & 0 & $14(12.7 \%)$ \\
\hline Shave & $5(11.1 \%)$ & $3(6.8 \%)$ & $5(23.8 \%)$ & $13(1 \mathrm{l} .8 \%)$ \\
\hline Repair & $2(4.4 \%)$ & 0 & 0 & $2(1.8 \%)$ \\
\hline Both articular and meniscal & $2 \mathrm{I}(46.7 \%)$ & $20(45.5 \%)$ & $12(57.1 \%)$ & $53(48.2 \%)$ \\
\hline Neither articular or meniscal & I (2.2\%) & 0 & 0 & I (0.9\%) \\
\hline
\end{tabular}

Abbreviation: SD, standard deviation. 
Table 3 Analysis of pain intensity (after movement) at 2 hours postsurgery (ITT population, LOCF)

\begin{tabular}{llll}
\hline Contrast & p-value ${ }^{\dagger}$ & Estimated difference & 95\% Cl* \\
\hline Primary contrast & & & \\
$\begin{array}{l}\text { Preemptive lumiracoxib } 400 \mathrm{mg} \text { vs postoperative } \\
\text { lumiracoxib } 400 \mathrm{mg}\end{array}$ & 0.602 & & $-2.0,1.0$ \\
Secondary contrast & & & -4.0 \\
Preemptive lumiracoxib $400 \mathrm{mg}$ vs placebo & 0.007 & -3.5 & $-9.0,-1.0$ \\
Postoperative lumiracoxib $400 \mathrm{mg}$ vs placebo & 0.052 & $-8.5,0.0$ \\
\hline
\end{tabular}

Notes: †Wilcoxon's rank sum test stratified by center; $* 95 \% \mathrm{Cl}$ for the Hodges-Lehmann estimate of the difference.

Majority of patients in the lumiracoxib preemptive and postoperative treatment groups assessed their medication as "excellent" ( $71.1 \%$ and $70.5 \%$, respectively) in contrast to $38.1 \%$ in placebo. This difference was significant in both preemptive $(p=0.012)$ and postoperative $(p=0.014)$ lumiracoxib groups compared to the placebo group.
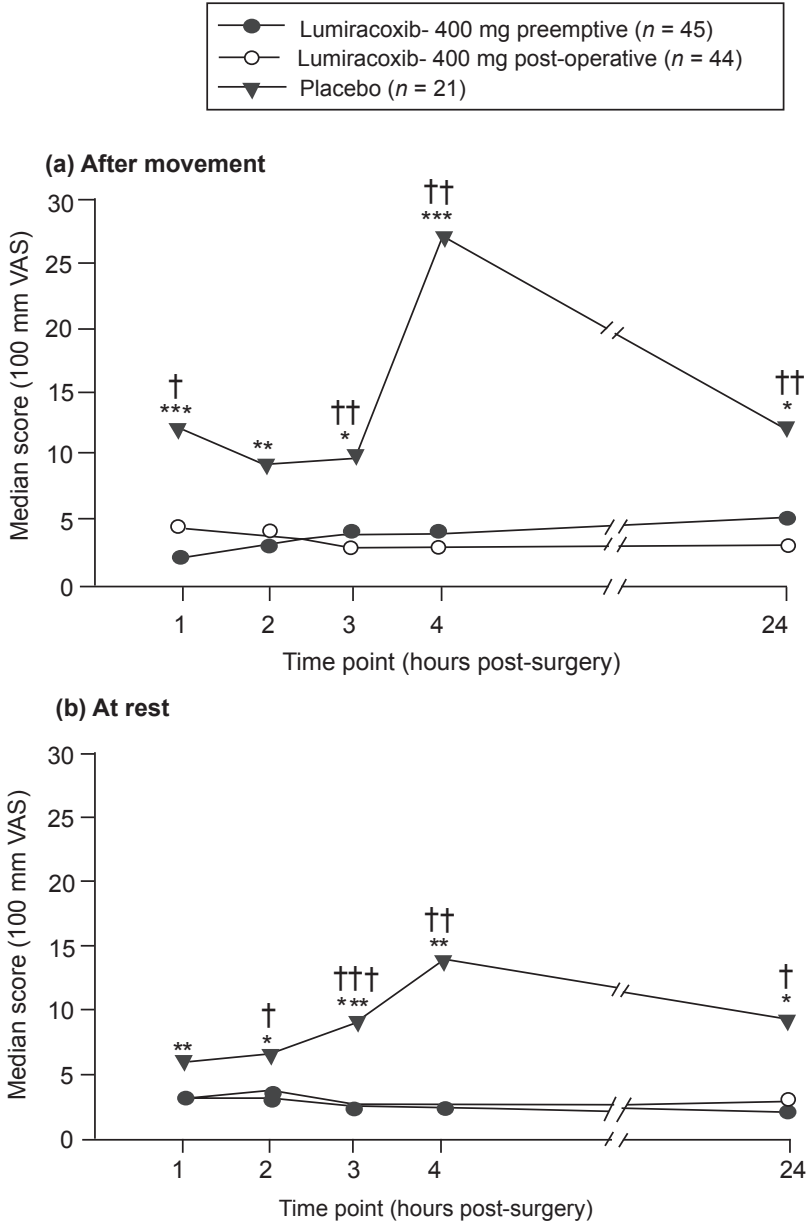

Figure 2 Pain intensity over time (ITT population, LOCF).

Notes: $* p \leq 0.05 ; * * p \leq 0.01 ; *^{* * *} p \leq 0.00$ I lumiracoxib $400 \mathrm{mg}$ preemptive vs placebo; ${ }^{\dagger} p \leq 0.05 ;{ }^{\dagger t} p \leq 0.0 \mathrm{I} ;{ }^{+t \dagger} p \leq 0.00$ I lumiracoxib $400 \mathrm{mg}$ postoperative vs placebo; No significant differences were observed between given preemptive and postoperative lumiracoxib $400 \mathrm{mg}$;Wilcoxon rank sum test stratified by center.
There was no significant difference between the active lumiracoxib groups ( $p=0.945)$.

Adverse events were mild or moderate and transient in nature. The proportion of patients with AEs was slightly greater for the placebo (4.8\%) group than the lumiracoxib preemptive $(4.4 \%)$ and postoperative $(4.5 \%)$ groups. No significant difference was observed in the AEs between the treatment groups. No SAEs were reported during this study (Table 5).

\section{Discussion}

Postoperative pain is mostly caused by several components and reasons involving ongoing sensory signals generated from the damaged tissue that may lead to modification in CNS function. The underlying principle behind preemptive analgesia is that the therapeutic intervention is made in advance to the pain rather than in reaction to it (Woolf and Chong 1993). This study found that administration of both preemptive and postoperative lumiracoxib $400 \mathrm{mg}$ was

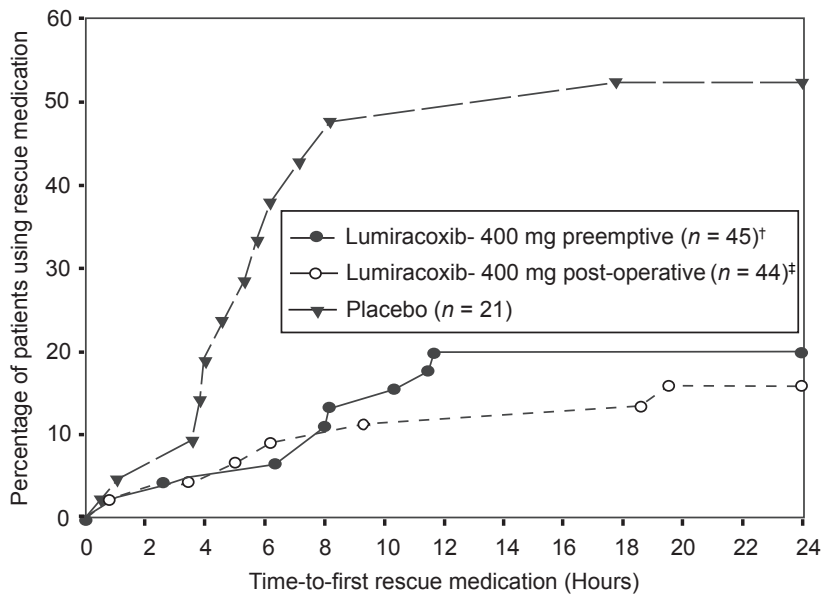

Figure 3 Time to first rescue medication (ITT population).

Notes: ${ }^{\dagger} p=0.003$ vs placebo, ${ }^{\ddagger} p=0.001$ vs placebo; $n=$ intent-to-treat patients per treatment group; $p$-values calculated using logrank test. 
Table 4 Summary of rescue medication use (safety population)

\begin{tabular}{|c|c|c|c|c|}
\hline & $\begin{array}{l}\text { Lumiracoxib } 400 \mathrm{mg} \\
\text { preemptive } \mathrm{N}=45\end{array}$ & $\begin{array}{l}\text { Lumiracoxib } 400 \mathrm{mg} \\
\text { postoperative } N=44\end{array}$ & Placebo $N=21$ & Total $N=110$ \\
\hline $\begin{array}{l}\text { No }(\%) \text { of patients who took } \\
\text { rescue medication }\end{array}$ & $9(20.0 \%)$ & 7 (I5.9\%) & II (52.4\%) & $27(24.5 \%)$ \\
\hline \multicolumn{5}{|c|}{ No (\%) of patients who took first dose of rescue medication } \\
\hline Prior to the I hour assessment & I (2.2\%) & I (2.3\%) & $0(0.0 \%)$ & $2(1.8 \%)$ \\
\hline Prior to the 2 hour assessment & I (2.2\%) & I (2.3\%) & I (4.8\%) & $3(2.7 \%)$ \\
\hline Prior to the 3 hour assessment & $2(4.4 \%)$ & I (2.3\%) & I (4.8\%) & $4(3.6 \%)$ \\
\hline Prior to the 4 hour assessment & $2(4.4 \%)$ & $2(4.5 \%)$ & $2(9.5 \%)$ & $6(5.5 \%)$ \\
\hline After the 4 hour assessment & $7(15.6 \%)$ & $5(\mathrm{I} I .4 \%)$ & $9(42.9 \%)$ & $21(19.1 \%)$ \\
\hline
\end{tabular}

significantly better than placebo in relieving pain following minor arthroscopic knee surgery and significantly delayed the first rescue medication intake compared to placebo. Moreover, the majority of patients in the lumiracoxib treatment groups assessed their medication as "excellent".

Preoperative administration of the COX-2 inhibitor reduces prostaglandin $\mathrm{E}_{2}$ and interleukin 6 levels in the cerebrospinal fluid and at the surgical site. These molecules are related to the development of postoperative pain, sleep disturbance, and poor functional recovery (Buvanendran et al 2006). Preoperative NSAID administration is generally associated with clear benefits in terms of reduced postoperative pain, analgesic and antiemetic consumption and patient satisfaction compared with placebo (Straube et al 2005). However in this study when preemptive dosing was compared to postoperative dosing, no statistically significant difference was observed. Also the time to first rescue medication intake was not statistically different between the active treatment groups.

There is a widespread belief in the efficacy of preemptive analgesia (Moiniche et al 2002). However the benefit of preemptive versus postoperative analgesia remains controversial in the literature. The superior efficacy of preemptive versus postoperative NSAID administration has been shown in certain clinical trials (Pedersen et al 1993; Reuben et al 2002; Ong et al 2005) while not in others (Murphy and Medley 1993; Norris et al 2001; Moiniche et al 2002). A metaanalysis of 20 trials comparing preincisional with postincisional NSAID or paracetamol found that some aspects of postoperative pain control were improved by preemptive treatment in four of the 20 trials. However, the overall data demonstrated that preemptive NSAIDs did not provide any superior analgesic benefit when compared with postincisional administration of these drugs (Moiniche et al 2002). This is in agreement with the findings in our study.

Reuben and colleagues (2002) however observed significant benefit of preemptive dosing compared to postoperative dosing in patients undergoing ambulatory arthroscopic knee surgery. The inclusion criteria, exact timing of preemptive and postoperative dosing relative to surgery and the anesthetic management in our study were comparable with this reference study. Nevertheless other factors, eg, the extent and nature of tissue damage, extent and duration of surgery (mean duration of surgery was almost half compared to our study), and pharmacokinetics of the agent (longer half life of refecoxib),

Table 5 Overall adverse events and affected system organ classes: $\mathrm{n}$ (\%) of patients (safety population)

\begin{tabular}{|c|c|c|c|c|}
\hline & $\begin{array}{l}\text { Lumiracoxib } 400 \mathrm{mg} \\
\text { preemptive } N=45 n(\%)\end{array}$ & $\begin{array}{l}\text { Lumiracoxib } 400 \mathrm{mg} \\
\text { postoperative } N=44 n(\%)\end{array}$ & Placebo $N=2$ I n (\%) & Total $N=\mid$ I 0 n (\%) \\
\hline Patients with $\mathrm{AE}(\mathrm{s})$ & $2(4.4)$ & $2(4.5)$ & I (4.8) & $5(4.5)$ \\
\hline \multicolumn{5}{|l|}{ System organ class } \\
\hline Cardiac disorders & 0 & 0 & I (4.8) & $\mathrm{I}(0.9)$ \\
\hline Angina pectoris & 0 & 0 & I (4.8) & I (0.9) \\
\hline Gastrointestinal disorders & I (2.2) & I (2.3) & 0 & $2(1.8)$ \\
\hline Abdominal pain & 0 & I (2.3) & 0 & $\mathrm{I}(0.9)$ \\
\hline Vomiting & I (2.2) & 0 & 0 & $\mathrm{I}(0.9)$ \\
\hline Nervous system disorders & I (2.2) & I (2.3) & 0 & $2(1.8)$ \\
\hline Headache & I (2.2) & I (2.3) & 0 & $2(1.8)$ \\
\hline
\end{tabular}


could have led to different study populations and different outcomes. The pain intensities reported in our study are lower than expected and might have limited the sensitivity to detect a further improved outcome in patients receiving preemptive dosing of lumiracoxib. Finally, the anesthetic management (especially intra-articular bupivacaine at the end of the surgery), as applied in the centers participating in our study, may have been more effective in controlling the development of postsurgical pain and may have played a confounding effect by masking the treatment differences on pain intensity, especially at the early time-points. Similar preemptive and postoperative efficacy comparison with other routinely used analgesics eg; paracetamol, ibuprofen, diclofenac, etc. warrant further studying.

In conclusion preemptive and postoperative administration of lumiracoxib $400 \mathrm{mg}$ was equally effective in relieving pain following minor arthroscopic knee surgery.

\section{Acknowledgments}

We would like to thank the investigators and the staff of the centers involved in this work for their expert collaboration and to the patients who participated in the study. The authors would also like to thank Dr Sajita Setia, a professional medial writer, for her help in the development of the manuscript and Dr Kirstin Stricker for the critical review of the manuscript.

\section{References}

Buvanendran A, Kroin JS, Berger RA, et al. 2006. Upregulation of prostaglandin $\mathrm{E}_{2}$ and interleukins in the central nervous system and peripheral tissue during and after surgery in humans. Anesthesiology, 104:403-10.

Buvanendran A, Kroin JS, Tuman KJ, et al. 2003. Effects of perioperative administration of a selective cyclooxygenase 2 inhibitor on pain management and recovery of function after knee replacement: a randomized controlled trial. JAMA, 290:2411-8.

Chan VW, Clark AJ, Davis JC, et al. 2005. The post-operative analgesic efficacy and tolerability of lumiracoxib compared with placebo and naproxen after total knee or hip arthroplasty. Acta Anaesthesiol Scand, 49:1491-500.

Daniels S, Gitton X, Zhou W, et al. 2008. Efficacy and tolerability of lumiracoxib $200 \mathrm{mg}$ once daily for treatment of primary dysmenorrhea: results from two randomized controlled trials. J Womens Health, 17:423-37.

Esser R, Berry C, Du Z, et al. 2005. Preclinical pharmacology of lumiracoxib: a novel selective inhibitor of cyclooxygenase-2. $\mathrm{Br} \mathrm{J}$ Pharmacol, 144:538-50.

Fleischmann R, Tannenbaum H, Patel NP, et al. 2008. Long-term retention on treatment with lumiracoxib $100 \mathrm{mg}$ once or twice daily compared with celecoxib $200 \mathrm{mg}$ once daily: a randomised controlled trial in patients with osteoarthritis. BMC Musculoskelet Disord, 9:32.

Fricke J, Davis N, Yu V, et al. 2008. Lumiracoxib $400 \mathrm{mg}$ compared With celecoxib $400 \mathrm{mg}$ and placebo for treating pain following dental surgery: a randomized, controlled trial. J Pain, 9:20-7.

Katz J. 2001. Pre-emptive analgesia: importance of timing. Can J Anaesth, 48:105-14.
Kellstein D, Ott D, Jayawardene S, et al. 2004. Analgesic efficacy of a single dose of lumiracoxib compared with rofecoxib, celecoxib and placebo in the treatment of post-operative dental pain. Int J Clin Pract, $58: 244-50$.

Kyle C, Zachariah J, Kasangra M, et al. 2006. Lumiracoxib 400 mg once daily is comparable to naproxen $500 \mathrm{mg}$ twice daily for treatment of acute muscular pain following soft tissue injury. Ann Rheum Dis, 65(Suppl II):241.

Legeby M, Sandelin K, Wickman M, et al. 2005. Analgesic efficacy of diclofenac in combination with morphine and paracetamol after mastectomy and immediate breast reconstruction. Acta Anaesthesiol Scand, 49:1360-6.

Moiniche S, Kehlet H, Dahl JB. 2002. A qualitative and quantitative systematic review of preemptive analgesia for postoperative pain relief: the role of timing of analgesia. Anesthesiology, 96:725-41.

Murphy DF, Medley C. 1993. Preoperative indomethacin for pain relief after thoracotomy: comparison with postoperative indomethacin. $\mathrm{Br}$ J Anaesth, 70:298-300.

Norris A, Un V, Chung F, et al. 2001. When should diclofenac be given in ambulatory surgery: preoperatively or postoperatively? J Clin Anesth, 13:11-5.

Ong KS, Seymour RA, Yeo JF, et al. 2005. The efficacy of preoperative versus postoperative rofecoxib for preventing acute postoperative dental pain: a prospective randomized crossover study using bilateral symmetrical oral surgery. Clin J Pain, 21:536-42.

Pedersen P, Nielsen KD, Jensen PE. 1993. The efficacy of Na-naproxen after diagnostic and therapeutic arthroscopy of the knee joint. Arthroscopy, 9:170-3.

Reuben SS, Bhopatkar S, Maciolek H, et al. 2002. The preemptive analgesic effect of rofecoxib after ambulatory arthroscopic knee surgery. Anesth Analg, 94:55-9.

Reuben SS, Buvanendran A. 2007. Preventing the development of chronic pain after orthopaedic surgery with preventive multimodal analgesic techniques. J Bone Joint Surg Am, 89:1343-58.

Reuben SS, Connelly NR. 2000. Postoperative analgesic effects of celecoxib or rofecoxib after spinal fusion surgery. Anesth Analg, 91:1221-5.

Robinson CM, Christie J, Malcolm-Smith N. 1993. Nonsteroidal antiinflammatory drugs, perioperative blood loss, and transfusion requirements in elective hip arthroplasty. $J$ Arthroplasty, 8:607-10.

Romsing J, Moiniche S. 2004. A systematic review of COX-2 inhibitors compared with traditional NSAIDs, or different COX-2 inhibitors for post-operative pain. Acta Anaesthesiol Scand, 48:525-46.

Schnitzer T, Burmester JG, Mysler RE, et al; TARGET Study Group. 2004. Comparison of lumiracoxib with naproxen and ibuprofen in the Therapeutic Arthritis Research and Gastrointestinal Event Trial (TARGET), reduction in ulcer complications: randomised controlled trial. Lancet, 364:665-74.

Scott G, Rordorf C, Reynolds C, et al. 2004. Pharmacokinetics of lumiracoxib in plasma and synovial fluid. Clin Pharmacokinet, 43:467-78.

Straube S, Derry S, McQuay HJ, et al. 2005. Effect of preoperative Cox-II-selective NSAIDs (coxibs) on postoperative outcomes: a systematic review of randomized studies. Acta Anaesthesiol Scand, 49:601-13.

Traversa G, Bianchi C, Da Cas R, et al. 2003. Cohort study of hepatotoxicity associated with nimesulide and other non-steroidal anti-inflammatory drugs. $B M J, 327: 18-22$.

Villar RN. 1994. Arthroscopy. BMJ, 308:51-3.

Willburger RE, Mysler E, Derbot J, et al. 2006. Lumiracoxib $400 \mathrm{mg}$ once daily is comparable to indomethacin $50 \mathrm{mg}$ three times daily for the treatment of acute flares of gout. Ann Rheum Dis, 65(Suppl II):566.

Woolf CJ, Chong MS. 1993. Preemptive analgesia - treating postoperative pain by preventing the establishment of central sensitization. Anesth Analg, 77:362-79.

Zelenakas K, Fricke JR Jr, Jayawardene S, et al. 2004. Analgesic efficacy of single oral doses of lumiracoxib and ibuprofen in patients with postoperative dental pain. Int J Clin Pract, 58:251-6. 